\title{
EL PRINCIPIO DE RESPONSABILIDAD DE HANS JONAS
}

\section{José Eduardo de Siqueira*}

Resumen: Este trabajo es una reflexión sobre la principal obra del filósofo alemán contemporáneo, Hans Jonas. Muestra la trayectoria intelectual de Jonas hasta llegar al rescate de la ética de la responsabilidad, que Max Weber sugiere en obras de comienzos del siglo. El Principio de la Responsabilidad de Jonas es una evaluación sumamente crítica de la ciencia moderna y de su "brazo armado", la tecnología. El filósofo muestra la necesidad que el ser humano tiene de actuar con cautela y humildad frente al enorme poder transformador de la tecnociencia.

Palabras clave: Bioética, Ciencia y Ética, Tecnología y Ética

\section{HANS JONAS' PRINCIPLE OF RESPONSIBILITY}

Abstract :This paper is a reflection on the main work of the german philosopher Hans Jonas. It shows his intellectual trajectory till the point of the rescueing of the ethics of responsibility, suggested in Max Weber's works of the beginning of this century. Jonas' principle of responsibility is an extremely critical analysis of modern science and its principal "armed arm", technology. The philosopher expounds the need all human beings have to act with caution and humility in face of the tremendous transforming power technoscience posseses.

keywords: bioethics, science and ethics, technology and ethics

\section{O PRINCÍPIO DE RESPONSABILIDADE DE HANS JONAS}

Resumo: Este trabalho é uma reflexão sobre a principal obra do filósofo alemão contemporâneo, Hans Jonas. Apresenta a trajetória intelectual de Jonas até o resgate da ética da responsabilidade que Max Weber sugere em obras do começo do século XX. O Princípio da Responsabilidade de Jonas é uma apreciação extremamente crítica da ciência moderna e de seu "braço armado", a tecnologia. $\mathrm{O}$ filósofo mostra que é necessário o ser humano agir com cautela e humildade ante o enorme poder transformador da tecnociência.

Palavras chaves: Bioética, Ciência e Ética, Tecnologia e Ética.

* Doctor en Medicina; Magíster en Bioética en la Universidad de Chile; Profesor de Clínica Médica y Bioética en la Universidad Estadual de Londrina. Vice-Presidente de la Sociedad Brasileña de Bioética.

Correspondencia: jtsique@sercomtel.com.br 
"El desafio de la futura bioética es que, más que nunca, poseemos conocimiento científico y capacidad tecnológica, sin embargo no tenemos la mínima noción de cómo utilizarlos, siendo que la crisis de nuestra era es la de haber adquirido un poder inesperado que debemos usar en medio del caos de un mundo postradicional, postcristiano y postmoderno".

\section{H.T. Engelhardt}

Hans Jonas nació en 1903 en Mönchenglandback, Alemania. De origen judío, recibió una formación humanística a través de la atenta lectura de los profetas hebreos. $\mathrm{Su}$ intensa vida intelectual fue relatada por él mismo en una conferencia dada en octubre de 1986 en la Universidad de Heidelberg, cuando se cumplieron 600 años de su fundación. Señala tres momentos marcantes en su formación filosófica. El primero comenzó en 1921 cuando, recién graduado, asiste a las clases de un maestro hasta entonces poco conocido, Martin Heidegger, en la Universidad de Freiburg. Según Jonas, él fue durante mucho tiempo su mentor intelectual. Cuando Heidegger se traslada a la Universidad de Marburg, Jonas lo acompaña. Allí conoce a Rudolf Bultmann, bajo cuya orientación elabora una tesis sobre la gnosis en el cristianismo primitivo, presentada en 1931. Como resultado de ese trabajo inicial, en 1934, publica el célebre Gnosis und spätantiker Geist, considerado por él mismo como el primer gran momento de su trayectoria como filósofo. Ese mismo año Jonas se ve obligado a abandonar Alemania, debido a la ascensión del nazismo al poder.

El segundo gran momento en la vida intelectual de Jonas ocurre en 1966, con la publicación de Phenomenon of Life, Toward a Philosophical Biology, obra en la que establece los parámetros para una filosofía de la biología. Abre un nuevo camino de reflexión sobre la precariedad de la vida y muestra el gran alcance filosófico de ese abordaje de la biología, pues vuelve a colocar la vida en una posición privilegiada y lejos de los extremos del idealismo irreal y del limitado materialismo. Presenta el equívoco de aislar al hombre de la naturaleza, imaginándolo desvinculado de las otras formas de vida. En el epílogo de la obra plantea una idea general de su proyecto, cuando escribe que "con la continuidad de la mente con el organismo, del organismo con la naturaleza, la ética se vuelve parte de la filosofia de la naturaleza (...) Solamente una ética fundada en la amplitud del ser puede tener significado" (1).

No es difícil reconocer la relación de esa etapa con el tercer y último momento de su vida intelectual. La búsqueda de una nueva ética desde las bases. Una ética de la responsabilidad, se vuelve la meta de Jonas. En 1979 publica Das Prinzip Verantwortung-Versuchi einer Ethic für die Tecnologische Zivilisation, traducido al inglés sólo en 1984.

Desde la juventud fue partidario del sionismo y al salir de Alemania va a Israel, donde se integra a una brigada judaica de autodefensa, permaneciendo como oficial de artillería hasta 1949. En la Segunda Guerra Mundial se alista en el ejército británico que lucha contra el nazismo. De esa época es la siguiente declaración: "Cinco años como soldado del ejército británico en la guerra contra Hitler (...) Alejado de los libros y de todo lo que hace parte de la investigación (...) Es que estaba comprometido algo más esencial. El estado apocalíptico de las cosas, la caída amenazadora del mundo (...) la proximidad de la muerte (...) todo eso fue terreno suficiente para propiciar una nueva reflexión sobre los fundamentos de nuestro ser y para volver a ver los principios por los cuales se guían nuestros pensamientos sobre aquéllos. Así volviendo a mis orígenes, fui lanzado de nuevo a la misión básica del filósofo y de su acción nata, que es pensar" (2).

Fue entonces la proximidad con la realidad de la muerte la que le hizo crecer la preocupación por la vida y ésa fue la meta que persiguió con gran determinación. Con ello lle- 
gó a desafiar la línea dominante, la filosofía del idealismo de la conciencia en la cual se había formado, al constatar que era la herencia del dualismo cartesiano y que mucho de la filosofía moderna se había estancado en la dicotomía mente-cuerpo. Era necesario volver a pensar la ética.

\section{La nueva ética propuesta por Jonas}

Hans Jonas señala como marco inicial del abuso del dominio del hombre sobre la naturaleza -causando su destrucción- el choque provocado por las bombas de Hiroshima y Nagasaki. En una entrevista publicada en el número 171 de la revista Esprit, del mes de mayo de 1991, dice textualmente: "Ello puso en marcha el pensamiento hacia un nuevo tipo de cuestionamiento, que maduró debido al peligro que representa para nosotros mismos nuestro poder, el poder del hombre sobre la naturaleza” (3). Sin embargo, más que la conciencia de un brusco apocalipsis, él tuvo el sentimiento de un posible apocalipsis gradual, resultante del creciente peligro presentado por los riesgos del progreso técnico global y su utilización inadecuada. Hasta ese entonces, el alcance de las prescripciones éticas estaba restringido al ámbito de la relación con el prójimo en el momento presente. Era una ética antropocéntrica y dirigida a la contemporaneidad. La moderna intervención tecnológica cambió drásticamente esa plácida realidad al poner la naturaleza al servicio del hombre y susceptible de ser alterada radicalmente. De ese modo, el hombre pasó a tener una relación de responsabilidad con la naturaleza, puesto que la misma se encuentra bajo su poder. Además de la intervención en la naturaleza extrahumana, es grave la manipulación del patrimonio genético del ser humano, que podrá introducir alteraciones duraderas de consecuencias futuras imprevisibles. Concluye diciendo que es preciso una nueva propuesta ética, que contemple no sólo la persona humana, sino la naturaleza también. Ese nuevo poder de la acción humana impone modificaciones en la propia naturaleza de la ética.

Todas las éticas tradicionales obedecían a premisas que se interrelacionaban mutuamente y que son las siguientes:

1) La condición humana, resultante de la naturaleza del hombre y de las cosas, permanecía fundamentalmente inmutable para siempre.

2) Con base en ese presupuesto, se podía determinar con claridad y sin dificultad el bien humano.

3) El alcance de la acción humana y de su consecuente responsabilidad estaba perfectamente delimitado.

Todo bien o mal que su capacidad inventiva pudiera proporcionar, se encontraba siempre dentro de los límites de la acción del ser humano, sin afectar la naturaleza de las cosas extrahumanas. La naturaleza no era objeto de responsabilidad humana, pues cuidaba de sí misma. La ética tenía que ver con el aquí y ahora. A cambio de los antiguos imperativos éticos, entre los cuales el imperativo kantiano constituye el parámetro ejemplar "Actúa de tal modo que el principio de tu acción se transforme en una ley universal", Jonas propone un nuevo imperativo: "Actúa de tal modo que los efectos de tu acción sean compatibles con la permanencia de una vida humana auténtica", o expresándolo de modo negativo: "No pongas en peligro la continuidad indefinida de la humanidad en la Tierra".

La tremenda vulnerabilidad de la naturaleza sometida a la intervención tecnológica del hombre muestra una situación inusitada, pues nada menos que toda la biósfera del planeta está expuesta a posibles alteraciones, lo cual hace imprescindible considerar que no sólo debe anhelarse el bien común, sino también el de toda la naturaleza extrahumana.

Otras posibles intervenciones en la naturaleza del ser humano revelan las proporciones del desafío para el pensamiento ético, con respecto a la condición humana propiamente dicha. Jonas plantea una serie de interrogantes críticas. Con respecto a la prolongación de la vida humana se pregunta:

¿ Hasta qué punto esto es deseable? Sobre el 
control de la conducta humana: ¿ Debemos inducir sentimientos de felicidad o placer en la vida de las personas a través de estímulos químicos? En relación a la manipulación genética, donde el hombre toma en sus manos su propia evolución: ¿ Estaremos capacitados para el papel de creadores? ¿Quiénes serán los escultores de la nueva imagen del hombre? ¿Se-gún qué criterios y en base a qué modelos? ¿El hombre tendrá el derecho de cambiar el patrimonio genético del propio hombre? Y advierte:

"Ante un potencial casi escatológico de nuestra tecnología, la ignorancia sobre las últimas consecuencias será, por sí sola, razón suficiente para una moderación responsable (...) Hay otro aspecto digno de mencionarse, los no nacidos carecen de poder (...) ¿Quéfuerza debe representar el futuro en el presente?" (4).

Delante de un poder tan extraordinario de transformaciones estamos desprovistos de reglas que ordenen las acciones humanas. Ese enorme desajuste sólo podrá repararse, de acuerdo con Jonas, mediante la formulación de una nueva Ética.

\section{El imperativo tecnológico y las dimensiones de la responsabilidad}

Al formular su imperativo de responsabilidad, Jonas está pensando no tanto en el peligro de la pura y simple destrucción física de la humanidad, sino en su muerte esencial, aquélla que adviene de la desconstrucción y la aleatoria reconstrucción tecnológica del hombre y del medio ambiente.

Hay una interacción entre la investigación y el poder. Esa nueva ciencia lleva a un conocimiento anónimo, que ya no es hecho para obedecer la verdadera función del saber durante toda la historia de la humanidad, la de ser incorporada a las conciencias en la búsqueda meditada y ponderada de la calidad de vida humana.

El nuevo saber es depositado en los bancos de datos y empleado de acuerdo con los medios disponibles y según las decisiones de los que sustentan el poder. Existe un verdadero asombro cognitivo, no solamente entre los ciudadanos, sino tambien entre los científicos, ellos mismos ultraespecializados y sin el dominio de todo el saber producido (5).

La investigación, por otro lado, es conducida por instituciones tecnoburocráticas. La tecnociencia va produciendo conocimientos que, sin ser objeto de reflexión crítica, se transforman en reglas impuestas a la sociedad, la cual, obediente a esa máquina ciega del saber, se proyecta tambaleante a lo largo de un oscuro túnel. En una famosa conferencia sobre la crisis de la ciencia europea, Husserl ya había identificado un agujero negro en el objetivismo científico. Era la ausencia de la conciencia de sí mismo. A partir del momento en que, de un lado, ocurrió el divorcio de la subjetividad humana, reservada a la filosofía, y la objetividad del saber que es propio de la ciencia, el conocimiento científico desarrolló las tecnologías más refinadas para conocer todos los objetivos posibles, pero quedó totalmente ajeno a la subjetividad humana. Se volvió ciego a la marcha de la propia ciencia, pues la ciencia no puede conocerse, no puede autoanalizarse, con los métodos que dispone hoy en día. Es lo que Morin denomina "ignorancia de la ecología de la acción"; o sea, toda acción humana, a partir del momento que tiene inicio, escapa de las manos del iniciante y entran en juego las múltiples interacciones propias de la sociedad, que la desvían de su objetivo y a veces le dan un destino opuesto al buscado al principio (6).

Para que haya responsabilidad, es preciso que exista un sujeto consciente. Lo que ocurre es que el imperativo tecnológico elimina la conciencia, elimina al sujeto, elimina la libertad en provecho de un determinismo. La superespecialización de las ciencias mutila y distorsiona la noción del hombre.

En varios países latinoamericanos, por ejemplo, la economía oficial menosprecia la noción de ciudadanía cuando elabora planes macroestructurales orientándose de acuerdo con criterios propuestos por los sectores financieros de los países centrales. La idea de hombre 
fue desintegrada. Las subespecialidades de la biología descartan la idea de vida humana integral, dejando en su lugar la concepción de moléculas, de genes, del A.D.N. La idea del hombre total no se contempla más en esa ciencia navegante de lo minúsculo. Ese divorcio entre los avances científicos y la reflexión ética hicieron que Jonas propusiera nuevas dimensiones para la responsabilidad, pues "la técnica moderna ha introducido acciones de magnitudes tan diferentes, con objetivos y consecuencias tan imprevisibles, que los marcos de la ética anterior ya no pueden contenerlos".

Las conquistas de la ciencia se expresan por la tecnología. La experiencia de la guerra, posteriormente, las investigaciones espaciales y los grandes laboratorios industriales ponen en evidencia que el desarrollo técnico depende estrechamente de la ciencia y el progreso de la ciencia depende fundamentalmente de la técnica. La ciencia crea nuevos modelos tecnológicos y la técnica crea nuevas líneas de objetivos científicos. La frontera es tan tenue que no se puede identificar dónde está el espíritu de la ciencia y la acción de la tecnología. Ciencia y tecnología, alma y cuerpo del nuevo imperativo que comanda los pasos de las investigaciones básicas, así como de la biología, de la física, de la neurología, de la genética, en fin de aquellos que consideramos los tan necesarios avances del conocimiento. Básica o aplicada, la investigación es siempre tecnocientífica, y por la simple observación de lo que sucede en un laboratorio de investigación no es posible distinguir si son procedimientos aplicados o no. Siempre y en todo lugar, el aparato tecnológico está presente y tiene un peso decisivo.

La técnica se convierte en la esencia del poder y pasa a ser la manifestación natural de las verdades contenidas en la ciencia. Si la ciencia teórica podía considerarse como pura e inocente, la tecnociencia, al ser intervencionista y modificadora, no lo es. La praxis siempre debe ser objeto de una reflexión ética. Exactamente por eso, las cuestiones éticas se colocan hoy en el plano de las investigaciones llamadas básicas, pues el proyecto de saber lleva inevitable- mente al hacer y al poder. En un contexto contemporáneo la pregunta kantiana “¿Qué puedo hacer?" debe contener otra: ¿Qué puedo hacer y qué puedo fabricar? El cuestionamiento ético, por lo tanto, ocurre en todos los instantes de la producción del conocimiento científico. La pregunta que Jonas formula es: ¿Qué podría satisfacer más en la búsqueda consciente de la verdad?". Recuerda las palabras de Oppenheimer que, después de años de trabajo en un laboratorio en busca de la fisión nuclear y al observar su aplicación en Hiroshima habría señalado que en aquel momento el científico puro tomó conocimiento del pecado. Desde entonces la paz de conciencia de los científicos quedó estremecida en todos los campos de investigación. Siempre estaba presente la duda: ¿Qué puedo hacer? Cuando hoy algunos científicos preocupados con sus quehaceres dicen enojados: “'Estamos perdiendo tiempo con esas reflexiones filosóficas que no conducen a nada y nos impiden que nos inclinemos sobre nuestros microscopios!", reciben la siguiente respuesta de Gadamer: "iNo es verdad! Las ideas generales son vitales; la necesidad que hay de integrar nuestro saber es mucho más universal que la universalidad de las ciencias!"

Ojalá Popper tuviera razón cuando afirma que "la historia de las ciencias, como la de todas las ideas humanas, es una historia de sueños irresponsables, de caprichos y de errores. Sin embargo, la ciencia es una de las raras actividades humanas, tal vez la única, en la cual los errores son señalados sistemáticamente y, con el tiempo, constantemente corregidos" (7). Frente a tal afirmación, se impone indagar sobre cómo considerar, entonces, a las víctimas fatales de la tecnociencia. ¿Qué decir, por ejemplo, de las víctimas de Hiroshima y Nagasaki? Por lo tanto, hoy no se concibe una ciencia cuyos fundamentos no sean una sólida conciencia ética del investigador, principalmente tomando en cuenta que él ya no suele ocupar el puesto de mando, sino que está al servicio de los que poseen el poder y no suelen cultivar preocupaciones de esa naturaleza. Es preciso considerar que la ciencia no tiene 
por misión providencial salvar a la humanidad, no obstante posee poderes ambivalentes sobre el desarrollo futuro de la humanidad.

Es indiscutible que hubo un avance extraordinario cuando la ciencia, en el siglo XVII se desvinculó de la religión y del Estado, creando desde entonces su propio imperativo: "conocer por conocer" sin respetar límites y gozando de total libertad. Hoy vivimos un momento de autocrítica. En las palabras de un pensador francés contemporáneo, para quien la guerra es un hecho demasiado complejo para que lo dejemos exclusivamente en manos de los generales, diríamos que la tecnociencia es demasiado poderosa para que la dejemos exclusivamente en manos de los científicos. Munford, en Técnica y civilización considera que hay que tener en cuenta el error que cometemos al subestimar nuestra capacidad de integrar tecnología y sociedad. Según el autor mencionado los nuevos inventos y tecnologías no están acompañados por una reflexión filosófica, porque se cree que es innecesario introducir juicios de valor entre máquinas y pensamientos (8).

En resumen, es de imaginar que los males que afligen a la sociedad humana puedan tener siempre una solución proporcionada por la ciencia. Se deduce la creencia de que con la ciencia se puede prescindir de los valores, lo que entonces pasa a ser, paradójicamente, el nuevo sistema de valores. La sociedad se olvidó de considerar que la técnica es autónoma con relación a la moral, a la cual no sólo no le debe atención, sino que no soporta ningún tipo de juicio moral. La técnica es completamente ajena a un juicio de esa naturaleza y evoluciona según una norma totalmente casual. El hombre no puede erigir su destino basado en un ciego orden de gran poder de transformación y destituído de valores éticos. En consecuencia, se hace imperiosa una nueva filosofía de la ciencia, lo que significa un cambio de paradigma. La cultura griega disponía de un saber de gran alcance, pero que no llevaba a ningún poder significativo de transformación. Al contrario, el saber moderno, de fuerte predominio técni- co, se hace acompañar por un extraordinario poder de transformación careciendo, sin embargo, de una reflexión ética que ejerza moderación sobre el imperial poder de la tecnociencia.

Los científicos, siendo humanos, no siempre admiten sus errores y limitaciones, lo que hace que la adopción de un nuevo paradigma sea un proceso de progresiva conversión que no implica la fuerza, sino el convencimiento lento y gradual. La ciencia tiene el compromiso primordial de una comprensión cada vez más detallada y refinada de la naturaleza. Es menester reconocer que los paradigmas raramente poseen todos los elementos convincentes de los antecesores, los cuales con no muy poca frecuencia prevalecen durante siglos, aunque contengan el germen de respuestas más adecuadas para los problemas que apuntan hacia el futuro. Así es el imperativo de Jonas, que aún no cumplió veinte años y se ofrece para sustituir el imperativo kantiano que ya conmemoró los doscientos.

Conservando todavía la perspectiva de considerar la responsabilidad de las acciones humanas, resulta innecesaria la afirmación de que el hombre, y solamente él en el reino animal, es capaz de cambiar el curso de la historia de la vida con sus intervenciones. En una ruta que se bifurca es el caminante quien tiene la opción de elegir. Los rumbos son diferentes, así como el destino final. Un camino puede terminar en un precipicio, mientras el otro en fuentes de aguas puras. Así parece ocurrir con la tecnología moderna que nos va presentando bifurcaciones cada vez más numerosas. Justamente en esos puntos de bifurcación se impone la cuestión de la elección que, casi siempre, presenta contornos apropiados a través de una decisión ética. Delante de las bifurcaciones que se presentan, cualquier cosa que hagamos, cualquiera que sean los criterios utilizados para nuestra opción, tenemos la percepción de que el producto final obtenido depende exclusivamente de nuestra decisión.

La responsabilidad del ser humano consigo mismo es indisociable de la que debe te- 
nerse en relación con todos los demás. Se trata de una solidaridad que lo conecta a todos los hombres y a la naturaleza que lo rodea. Por tanto, resulta innegable que la dedución final de esa reflexión busque atender también lo universal. Concluimos con Jonas que el ser humano requiere contestar con su propio ser a una noción más amplia y radical de la responsabilidad, la referente a la naturaleza humana y extrahumana, ya que la tecnología moderna permite acciones transformadoras en un espectro que va desde el genoma humano hasta el plan cósmico.

La antigua idea de naturaleza se sometía al inalcanzable orden natural que señalaba los contornos de las normas éticas. Hoy trabajamos con una concepción totalmente distinta de la naturaleza. El curso de la naturaleza no depende más de una ley superior, que reserva al ser humano la condición de espectador. Muy al contrario, hoy él es el agente de las transformaciones y tiene a su merced toda la existencia, y en ella interviene cuando se le ocurre. La idea de naturaleza debe, por lo tanto, entendérsela como propiedad, dominio del hombre. Tal vez, ni siquiera el mismo Bacon hubiera podido concebir un poder tan extraordinario, un dominio tan absoluto de la naturaleza. Ante esa realidad, es imposible no interponer a la actitud científica exigencias de una nueva responsabilidad ética.

Lo que caracteriza el imperativo de Jonas es su orientación hacia el futuro, más exactamente hacia un futuro que ultrapase el horizonte cerrado, en el interior del cual el agente transformador pueda reparar daños causados por él, o sufrir la condena de los eventuales delitos que él haya perpetrado. Según Paul Ricoeur, el vínculo entre la responsabilidad y el peligro para la humanidad, impone que al concepto de responsabilidad se adicione un aspecto que lo distinga definitivamente de la imputabilidad. Se considera responsable, se siente afectivamente responsable aquél a quien le es confiada la guarda de algo perecedero. ¿Y qué hay más perecedero que observar a la vida marcharse hacia la muerte por la inconsecuen- te intervención del hombre? (9). Así se comprende mejor la idea de vida que se presenta en la formulación del imperativo de Jonas. Ante la posibilidad escatológica de que la muerte sustituya a la vida, se comprende por qué el lejano futuro es el lugar de un temor específico, para el cual Jonas introduce la figura de la "heurística del temor". Un temor cuyos objetivos son los posibles peligros que amenazan a la humanidad en el plano de su permanencia, de su supervivencia. Son emblemáticos los peligros que afectan el ecosistema, dentro del cual se desarrollan las actividades humanas, o los que resultan de la manipulación biológica aplicada a la reproducción humana, o a la identidad genética de la especie humana, o todavía a la intervención química o quirúrgica sobre el comportamiento del hombre. En suma, debido a la técnica, el hombre se volvió peligroso para el hombre, en la medida que pone en peligro los grandes equilibrios cósmicos y biológicos que constituyen los cimientos vitales de la humanidad.

La amenaza que el hombre hace pesar sobre el hombre toma, de algún modo, el lugar de las amenazas a las cuales los otros seres vivos ya están sometidos debido a las acciones humanas. A la vulnerabilidad de la vida, el hombre de la era tecnológica añade un factor desintegrador suplementario, el de su propia obra. La vida en el planeta tuvo sus reglamentos durante mucho tiempo, pues la naturaleza se constituía en un cerco infranqueable para la actuación humana. Sin embargo, la acción del hombre, al dejar de ser regida por fines naturales, se transforma en el centro de un desequilibrio específico. Por su dimensión cósmica, por sus efectos acumulativos e irreversibles, las técnicas introducen distorsiones tan definitivas que crean una dimensión de peligro sin precedentes en la historia de la vida. La preservación de la vida siempre tuvo un costo, pero con el hombre moderno ese costo, puede ser el de la destrucción total. En proporción al aumento del grado de peligro del hombre crece en importancia su responsabilidad como tutor de todas las formas de vida. 
Umberto Eco presenta una apreciación que viene al caso sobre las preocupaciones del hombre moderno por la responsabilidad, expresándose de la siguiente manera: "El progreso material del mundo agudizó mi sensibilidad moral, amplió mi responsabilidad, aumentó mis posibilidades, dramatizó mi impotencia. Al hacerme más dificil ser moral, hace con que yo, más responsable que mis antepasados y más consciente, sea más inmoral que ellos y mi moralidad consiste precisamente en la conciencia de mi incapacidad" (10).

El principio de responsabilidad pide que se preserve la condición de existencia de la humanidad, muestra la vulnerabilidad que la acción humana suscita a partir del momento en que él se presenta ante la fragilidad natural de la vida. El interés del hombre debe identificarse con el de otros miembros vivos de la Naturaleza, pues ella es nuestra morada común. Nuestra obligación se hace incomparablemente mayor en función de nuestro poder de transformación y la conciencia que tenemos de todos los eventuales daños causados por nuestras acciones, como bien observó Eco. La manutención de la naturaleza es la condición de sobrevivencia del hombre y en el ámbito de ese destino solidario Jonas habla de dignidad propia de la naturaleza. Preservar la naturaleza significa preservar al ser humano. No se puede decir que el hombre es sin que se diga que la naturaleza también es. Así, por supuesto, el sí a la naturaleza se volvió una obligación del ser humano. Lo que el imperativo de Jonas establece, en efecto, no es sólo que existan hombres después de nosotros, sino precisamente que sean hombres de acuerdo con la idea vigente de humanidad y que habiten este planeta con todo el medio ambiente preservado.

Otro aspecto que merece atención es el lado subjetivo de la responsabilidad, o sea, de qué manera el promotor de la acción asume su intervención, sea en un momento pasado o en acciones futuras. En el caso de las acciones pasadas que culminaron en perjuicios, el sentimiento de responsabilidad se encuentra muy estrechamente relacionado con la sensación de remordimiento. Es el sentimiento de lo irremediable, pues se trata del sufrimiento moral que sobreviene de la impotencia para revocar los efectos de una catástrofe generada por una acción pretérita. Un ejemplo paradigmático de esa situación lo encontramos en la apreciación de Oppenheimer sobre los efectos desvastadores de la bomba atómica que nació de la búsqueda inicial pura e imparcial del conocimiento de la fisión nuclear. Los daños observables que se presentan para la reflexión del agente intelectual de la transformación movilizan en él sentimientos de angustia y sufrimiento. La prescripción ética no se impone como coerción, sino como una fuerte exhortación dirigida a la libertad del agente de transformación. $Y$ es justamente como una exhortación singular que la responsabilidad ética se convierte en sentimiento. Es en ese campo del comportamiento que Jonas pretende legislar. Es en ese momento que la existencia se vuelve vulnerable y su esencia puesta en juego. Reflexionemos, por ejemplo, sobre la responsabilidad ética relativa al otro, al ser humano presente, real y objeto de acciones transformadoras de la ciencia. El otro, en la calidad de ser humano, guarda en su existencia una exigencia radical de respeto pues detenta un mandato de vida que, por sí solo, habla elocuentemente de la necesidad de manutención de su integridad. Es inimaginable, por ejemplo, el Proyecto Genoma Humano sin la presencia de la reflexión ética como principio, medio y fin de todas sus posibles intervenciones (11).

Lo mismo puede decirse de las acciones sobre la naturaleza extrahumana. Es elemental el conocimiento de las repercusiones sobre la salud humana, producidas por el deterioro del medio ambiente. Todos, aunque de modo superficial, conocen los posibles cataclismos que ocurrirán como consecuencia del supercalentamiento del planeta, o de la progresiva destrucción de la capa de ozono, o aun, de la incontrolable destrucción de la vegetación de las ya escasas reservas forestales del planeta. En el momento actual hay una representación de un futuro que tal vez no se realice, pero 
que sin embargo, expone su testimonio en el presente como caracterización de una desdicha, como imagen de lo no querido y, sobre todo, presentando enfáticamente la necesidad de instituir un nuevo estatuto de responsabilidad de los hombres que tenga por objetivo el sustento de la vida humana y extrahumana. Así se comprende la tesis de Jonas, como una ética orientada hacia el futuro.

Por lo tanto, la responsabilidad en la ética es la articulación entre dos realidades, una subjetiva y otra objetiva. Es forjada por esa fusión entre el sujeto y la acción. Al mismo tiempo, hay también un aspecto de descubrimiento que se revela en la acción propiamente dicha y sus consecuencias. El orden ético está presente, no como realidad visible, sino como un llamado sensato que pide calma, prudencia y equilibrio. A este nuevo orden Jonas le da el nombre de Principio de Responsabilidad.

\section{Referencias}

1. Jonas H. The phenomenon of life: toward a philosophical biology. New York: Harper and Row; 1966.

2. Bernstein RJ. Rethiking responsibility. Hastings Center Report 1995; 25 (7 Special Issue): 13-20.

3. Greisch J. De la gnose au Principe de Responsabilité (un entretien avec Hans Jonas). Esprit 1991; (171): 5-21.

4. Jonas H. El Principio de Responsabilidad: ensayo de una ética para la civilización tecnológica. Barcelona: Herder; 1995.

5. Morin E. El método: la naturaleza de la naturaleza. $3^{\mathrm{a}}$ ed. Madrid: Cátedra; 1993.

6. Morin E. El método: la vida de la vida. Madrid: Cátedra; 1983.

7. Moles A. As ciências do impreciso. Rio de Janeiro: Civilização Brasileira; 1995.

8. Munford L. Técnica y civilización. Madrid: Alianza; 1992.

9. Ricoeur P. A região dos filósofos. Sao Paulo: Loyola; 1992.

10. Eco U. De la responsabilidad moral como producto tecnológico: diario mínimo. Barcelona: Península; 1973.

11. Siqueira JE. Ética e tecnociencia: uma abordagem segundo o princípio da responsabilidade de Hans Jonas. Londrina: Ed. UEL; 1998. 